\title{
Assessing the Relative Importance of Key Quality of Life Dimensions for People With and Without a Disability: an Empirical Ranking Comparison Study.
}

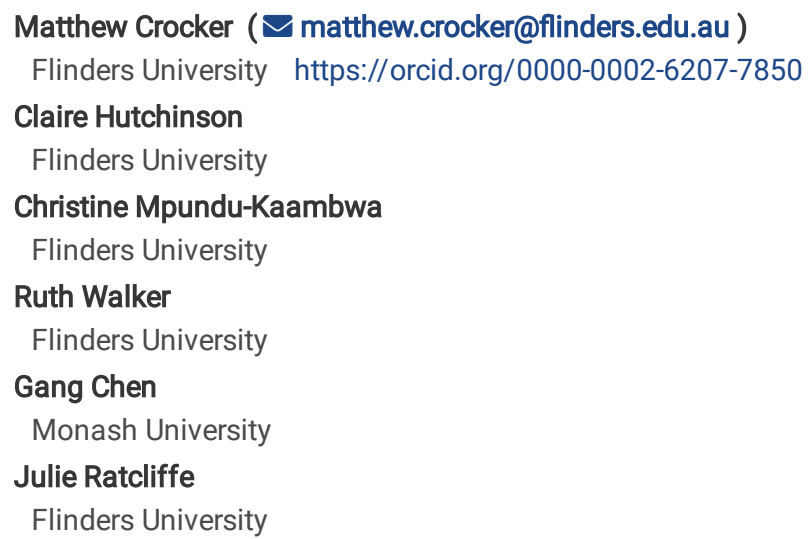

Research Article

Keywords: health economics, economic evaluation, disability, preferences, quality of life

Posted Date: July 13th, 2021

DOI: https://doi.org/10.21203/rs.3.rs-691502/v1

License: @ (i) This work is licensed under a Creative Commons Attribution 4.0 International License. Read Full License

Version of Record: A version of this preprint was published at Health and Quality of Life Outcomes on December 1st, 2021. See the published version at https://doi.org/10.1186/s12955-021-01901-x. 


\section{Abstract}

Background: In economic evaluation, the quality of life of people with a disability has traditionally been assessed by applying established generic preference-based measures. To provide robust measurement of the effectiveness of programs designed to improve the quality of life of people living with a disability, preference-based measures need to be sufficiently sensitive to detect incremental changes in the quality of life dimensions that are most important to people who have a disability.

Methods: An online survey was developed and administered Australia wide to two different population samples. The first sample $(n=410)$ comprised adults (aged 18 years and above) with a disability $(n=208)$ and family carers of person/s with a disability $(n=202)$. The second sample included adults (aged 18 years and above) without disability $(n=443)$. Respondents were asked to rank the importance of 12 quality of life dimensions extracted from the content of established preference based quality of life measures (EQ-5D, AQoL and ASCOT) in terms of their relative importance to their overall quality of life. The results were combined, and the preference rankings between groups were compared.

Results: People with a disability placed relatively higher importance on broader quality of life dimensions (e.g. Control, Independence, Self-care) relative to health status focused dimensions (e.g. Vision, Hearing, Physical mobility), whereas these two dimension categories were less clearly differentiable for the 'without disability' group. The biggest differences between the groups in what dimensions were ranked as the most important (i.e. $1^{\text {st }}$ preference) were in: Vision ('with disability' $=10^{\text {th }}$, 'without disability' $=4^{\text {th }}$ ), Self-care ('with disability' $=3^{\text {rd }}$, 'without disability' $=7^{\text {th }}$ ) and $M e n t a l$ well-being ('with disability' $=6^{\text {th }}$, 'without disability' $=2^{\text {nd }}$ )

Conclusions: Quality of life preferences for people with a disability differ to those without a disability. As quality of life is a key outcome for economic evaluation and for assessing the impact of disability care policy and practice in Australia and internationally, it is important that new preferencebased measures of quality of life are developed which are sufficiently sensitive to and incorporate the quality of life preferences of people with a disability.

\section{Background}

The introduction of personalised budgets for people with assessed care needs due to their disability, is the most significant policy change introduced as a part of Australia's National Disability Insurance Scheme (NDIS) to improve Australians' access to disability services and supports (1). This significant policy change follows similar moves to promote personalisation and consumer directed care in the disability care sectors of other countries, including the United Kingdom, the USA, Canada and the Netherlands (2). Personalisation aims to empower consumers (people with a disability and family carers) to exercise choice and control over the care and support that they receive, and to make decisions about how their allocated funding is spent. Detailed consideration of the cost effectiveness of alternative services and supports through the application of an economic evaluation framework can provide a valuable resource for consumers and disability service providers to make informed choices about their care. Necessarily, the measurement of costs plays an important role in determining the value for money of services and supports. However, the measurement and valuation of quality of life also forms an important component of this process as it is the main outcome measure used in economic evaluation (3). To that end, there is a need to ensure that processes are in place to accurately capture the quality of life preferences of people with a disability.

Whilst there is a developing literature which has documented the differences in quality of life preferences between younger and older people (4-6), there is less known about the preferences of people living with a disability. Research has been conducted on populations with specific conditions to better understand what factors affect their quality of life (7-9), but little attention has been paid to better understanding the preferences of a broader, community based population with a disability.

The challenge to accurately measure a person's quality of life has been a longstanding issue for health economists (10). Economic evaluation focuses on assessing the efficiency of resource allocation in terms of how different distributions of resources affect the quality of life of the population under consideration. To compare the effectiveness of different interventions in this context, generic preference-based measures of quality of life have become the preferred method of assessment (11), whereby individual responses to a measure can be converted into summary quality of life scores or utilities using the preference-based scoring algorithm pertaining to the measure. Scoring algorithms are typically developed from the quality of life preferences of large general population based samples; the majority of whom are living without disability (3). One of the most widely used generic preference-based measures is the EQ-5D tool. It has been used extensively to measure health related quality of life in patient population samples and in large population-based studies $(12,13)$. Another generic preference-based measure developed in Australia, which has also been utilised in these contexts, is the Assessment of Quality of Life Four Dimension (AQoL-4D). Whilst both of these measures have a generic focus and application, the Adult Social Care Outcome Toolkit (ASCOT) was developed more specifically for application in social care to capture the effect that social care-related needs (not just health-related needs) have on an individual's quality of life (14). Refining generic preference-based measures of quality of life to more accurately reflect the quality of life preferences important to different populations will continue to be an important area of development within health economics (3).

As the world's population continues to age, more and more people will fall under the World Health Organisation's definition of disability (15): an umbrella term for impairments of body function or structure, activity limitations or participation restrictions (16). In 2020, 4.4 million Australians (18 
per cent of the population) were living with a disability (16). If Governments are to be effective in providing care and support that maximises the quality of life of people with disabilities, it is important that their perspectives are considered and incorporated into outcome metrics for quality assessment and economic evaluation.

\section{Methods}

The main aim of this study was to investigate the relative importance rankings of 12 key quality of life dimensions mapped from three commonly applied generic preference-based measures (EQ-5D, AQoL-4D and the ASCOT) between population samples with and without a disability. The results of two, separate online surveys were combined to compare the quality of life preferences between people with and without a disability. Both surveys were developed for an online mode of delivery and were administered by PureProfile - an online panel company. Participants were recruited by PureProfile from their existing panel (comprising over 452,000 Australian adults living with and without disability in the community), and eligible respondents completed the survey after providing informed consent. The first survey ('general population') was administered to a general population sample. Eligible respondents were Australian adults aged 18 years and older who were able to read and respond to a survey in the English language. The second survey ('with disability') was administered to a targeted population sample of Australian adults aged 18 years and older who identified as having some form of disability and family carers of a person with a disability who was unable to respond for themselves (e.g. due to severe physical and/or intellectual impairment). The carers were instructed to complete the survey taking the person's perspective, thinking about how the person who they care for would respond if they were able.

The survey consisted of four sections. In Section A respondents were asked to complete the ASCOT (four-level self-completion questionnaire) and AQoL-4D measures. To reduce the potential for ordering effects, the order of which survey measure appeared first was randomised within each survey group. Section B asked the survey respondents to rank a list of 12 quality of life dimensions in order of their importance to their quality of life. The 12 quality of life dimensions were extracted from the content of the EQ-5D, the AQoL-4D and the ASCOT instruments. A mapping technique was applied to identify common quality of life dimensions across the instruments. The results of the mapping exercise can be found in Appendix 1 . To reduce the potential of any ordering effects, the order in which the quality of life dimensions were presented in Section B was randomised for each survey respondent across both surveys. Respondents were asked to drag and drop a total of 12 quality of life dimension cards (Fig. 1) in order of their relative importance in determining their overall quality of life. The first subset of quality of life dimensions were more specifically focused on health status (e.g. physical mobility, pain, mental health, sleep, hearing, vision). The second subset were classified as dimensions which may affect an individual's broader quality of life (independence, self-care, control, social relationship, safety, dignity). Section $\mathrm{C}$ comprised of a series of brief sociodemographic questions. The final section of the survey asked respondents to indicate how difficult they found the survey to complete on a scale from 1 to 4 , where 1 indicated 'not difficult' and 4 indicated 'very difficult'.

\section{Exclusion criteria}

To compare the quality of life preferences between the two surveyed groups, all responses from the 'general population' survey were screened to generate the general population without disability group. Respondents were excluded if they indicated a 'yes' response to one or more of the following questions.

- Do you have a long-term disability, illness or medical condition?

- Do you need any help looking after yourself?

- When doing household tasks (e.g. cooking, cleaning) do you need any help?

- Do you need any help to get around your home and community?

- Do you currently receive any care support or services which enable you to remain living at home?

Socio-economic status

The socio-economic status of survey respondents ('with disability' and 'without disability' sample populations) was calculated according to the Australian Bureau of Statistics' Socio-Economic Indexes for Areas (SEIFA) (17). The SEIFA is a group of indexes which ranks the geographic area in which the individual resides according to details obtained from the Australian Census of Population and Housing (17). According to their residential postcode, respondents from both surveyed groups were assigned a SEIFA Index of Relative Socio-economic Advantage and Disadvantage score (18). Respondents were then placed into the following groups of advantage according to their score: Low (1-4), Medium (5-7) and High (8-10) (19, 20).

Analysis

All data analysis was completed in R version 4.0.3 (21). Descriptive summary statistics and between group differences were calculated. Normality was tested for all data using the Shapiro-Francia normality test and statistically significant differences between categorical groups were explored using Pearson's Chi-squared test. For continuous variables, the Wilcoxon rank-sum test with continuity correction was used to assess for differences between groups (22). To assess the similarities between rankings of the 12 quality of life dimensions, intraclass correlation coefficient (ICC) estimates and their $95 \%$ confidence intervals were calculated based on a two-way random effects model (23). Both single ICCs (estimated correlations between individual rankings of the same quality of life dimensions) and average ICCs (estimated correlations between average rankings made on the same 
quality of life dimensions by different rankers) were estimated (22). An ICC under 0.5 was interpreted as being indicative of poor reliability, values between 0.5 and 0.75 were classified as moderate reliability, 0.75 to 0.9 good reliability, and an ICC greater than 0.9 indicated excellent reliability (23).

The quality of life dimensions were ranked using a similar approach to that adopted by Ratcliffe et al. (2017) which compared the quality of life preferences of younger (aged 18-64) and older people (aged 65 years and above). For example, a quality of life dimension that was ranked as the most important factor by a survey respondent, received a score of 12 points. The second most important dimension was assigned 11 points, and this pattern occurred until the 12th ranked quality of life dimension received 1 point. The total number of points allocated to each quality of life dimension was summed for each group (with and without disability) and then presented as a percentage of the total number of available points. This allowed for direct comparison between the preference orderings of people with disability and without disability.

\section{Results}

For the 'general population' survey, 2124 individuals were approached, of whom $1532(72 \%)$ consented to participate and 1000 fully completed the survey ( $47 \%$ of those initially approached). As per the exclusion criteria, 557 respondents were removed from the 'general population' group which left 443 survey respondents who were classified as the 'without disability' group population.

For the 'with disability' survey, 3538 persons provided informed consent, of which 2988 (84\%) were screened out as they did not identify as having a disability or as providing care for someone with a disability. A further 140 (4\%) started the survey but did not complete it. A total of 410 people (11\% of those who provided consent) fully completed the survey.

Data from the 'with disability' $(n=410)$ and 'without disability' $(n=443)$ surveys were combined. A dummy variable $(1=$ with disability) was assigned to the combined group to identify respondents who have a disability (or who were responding on behalf of someone with a disability).

The 'with disability' group consisted of proxy $(n=202)$ and self-reported $(n=208)$ responses. The disability characteristics of both the proxy and selfreported respondents were similar. With respect to disability characteristics, there was no statistically significant difference between the self-reported and proxy-reported sub-groups: Onset of disability $\left(X^{2}=2.92, p=0.09\right)$ and Type of disability $\left(X^{2}=5.57, p=0.06\right)$.

Table 2

Respondent characteristics of the 'with disability' group

\begin{tabular}{|c|c|c|c|c|}
\hline Characteristics & $\begin{array}{l}\text { Self-reported }(n= \\
\text { 208) }\end{array}$ & $\begin{array}{l}\text { Proxy-reported }(n= \\
202)\end{array}$ & $\begin{array}{l}\text { 'with disability' ( } \mathrm{n}= \\
410)\end{array}$ & $\begin{array}{l}\text { Test of difference (Self vs Proxy- } \\
\text { reported) }\end{array}$ \\
\hline \multicolumn{5}{|c|}{ Onset of disability: $\mathrm{n}(\%)$} \\
\hline Birth & $29(13.94)$ & $41(20.30)$ & $70(17.07)$ & $x^{2}=2.92, p=0.09$ \\
\hline Acquired & $179(86.06)$ & $161(79.70)$ & 340 (82.93) & \\
\hline \multicolumn{5}{|l|}{ Type of disability: n (\%) } \\
\hline Intellectual & $37(17.79)$ & $47(23.27)$ & $84(20.49)$ & \\
\hline Physical & $136(65.38)$ & 109 (53.96) & $245(59.76)$ & $x^{2}=5.57, p=0.06$ \\
\hline $\begin{array}{l}\text { Both intellectual and } \\
\text { physical }\end{array}$ & $35(16.83)$ & $46(22.77)$ & $81(19.76)$ & \\
\hline $\mathrm{X}^{2}$ is a Chi-squared te & & & & \\
\hline
\end{tabular}

To justify the pooling of the responses (i.e. treating self and proxy-reported responses as one group rather than two separate ones), it was important that irrespective of who responded (proxy or self-reported) there was a high average ICC within the pooled group. A high average ICC indicated that the quality of life preferences reported by the proxies were like the self-reported preferences.

Table 3 presents the ICC statistics. The ICC estimates based on individual (single) ranking across both 'with disability' and 'without disability' groups were lower than the recommended minimum reliability of 0.5 , indicating poor reliability (23). This implies that there was very little similarity between individual rankings for the same quality of life dimensions across both surveyed groups. Whereas the average ICCs (averages of rankings) for the same quality of life dimension among several rankers in both groups were greater than 0.9 , denoting excellent reliability ('with disability' $=0.989$ and 'without disability' = 0.987). The high average ICCs indicate a high level of similarity/agreement within the 'with disability' and 'without disability' groups. 
Table 3

Absolute agreement Intraclass Correlation (ICC) for rankings of 12 Quality of life dimensions

\begin{tabular}{|c|c|c|c|c|c|c|c|c|}
\hline \multirow[b]{2}{*}{ Type } & \multirow[b]{2}{*}{ Group } & \multirow[b]{2}{*}{ ICC } & \multicolumn{2}{|c|}{ 95\% Confidence interval } & \multicolumn{4}{|c|}{$\mathrm{F}$ test with true value $=0$} \\
\hline & & & Lower bound & Upper bound & Value & df1 & $\mathrm{df} 2$ & p-value \\
\hline \multirow[t]{2}{*}{ Single ${ }^{a}$} & With disability $(n=410)$ & 0.186 & 0.101 & 0.399 & 86.7 & 11 & 4499 & $<0.000$ \\
\hline & Without disability $(n=443)$ & 0.143 & 0.076 & 0.327 & 68.9 & 11 & 4862 & $<0.000$ \\
\hline \multirow[t]{2}{*}{ Average $^{b}$} & With disability $(n=410)$ & 0.989 & 0.979 & 0.996 & 86.7 & 11 & 4499 & $<0.000$ \\
\hline & Without disability $(n=443)$ & 0.987 & 0.987 & 0.995 & 68.9 & 11 & 4862 & $<0.000$ \\
\hline \multicolumn{9}{|c|}{ ICC calculation performed in R version 4.0.3 using the package irr().Single and average rating, absolute agreement, twoway random effects } \\
\hline \multicolumn{9}{|c|}{${ }^{a}$ Agreement between individual rankings } \\
\hline
\end{tabular}

The characteristics for each group are presented in Table 4. The mean age for the 'with disability' and 'without disability' groups was very similar: 53.6 (18.5) and 52.7 (17.9) years respectively. Similarly, there was no statistically significant difference in the distribution of ages between the groups $\left(X^{2}=\right.$ $8.35, p=0.14)$ and there was approximately an equal proportion of women in both groups $\left(X^{2}=0.67, p=0.41\right)$. Differences in self-reported levels of general health were observed between the two groups with people with a disability reporting lower levels of health relative to people without disability, and these differences were found to be statistically significant $\left(X^{2}=366.63, p<0.001\right)$. In the 'with disability' group, 58\% of respondents ( $\left.n=236\right)$ indicated that their health was 'Fair' or 'Poor'. In comparison, $71 \%$ of respondents $(n=312)$ in the 'without disability' group identified that their health was 'Excellent' or 'Very good'. There was no statistically significant difference between the groups' levels of socio-economic advantage according to SEIFA classifications $\left(X^{2}=2.50, p=0.29\right)$. 
Table 4

Respondent characteristics according to respondent group

\begin{tabular}{|c|c|c|c|c|}
\hline Characteristics & $\begin{array}{l}\text { With disability }(n= \\
410)\end{array}$ & $\begin{array}{l}\text { Without disability }(n= \\
\text { 443) }\end{array}$ & $\begin{array}{l}\text { Total sample }(n= \\
\text { 853) }\end{array}$ & $\begin{array}{l}\text { Test of difference (With vs Without } \\
\text { disability) }\end{array}$ \\
\hline \multicolumn{5}{|l|}{ Age in years: } \\
\hline Mean (SD) & $53.6(18.5)$ & $52.7(17.9)$ & $53.1(18.2)$ & $Z^{*}=90723, p=0.98$ \\
\hline Median (IQR) & $56(38,66)$ & $55(36,68.5)$ & $56(37,68)$ & \\
\hline \multicolumn{5}{|c|}{ Age Group: n (\%) } \\
\hline $18-29$ & $50(12.20)$ & $62(14.00)$ & $112(13.13)$ & \\
\hline $30-39$ & $56(13.66)$ & $74(16.70)$ & $130(15.24)$ & \\
\hline $40-49$ & $61(14.88)$ & $56(12.64)$ & $117(13.72)$ & $X 2=8.35, p=0.14$ \\
\hline $50-59$ & $65(15.85)$ & $46(10.38)$ & $111(13.01)$ & \\
\hline $60-69$ & $91(22.20)$ & $112(25.28)$ & $203(23.8)$ & \\
\hline $70+$ & $87(21.22)$ & 93 (20.99) & $180(21.1)$ & \\
\hline \multicolumn{5}{|l|}{ Gender: n (\%) } \\
\hline Female & $205(50)$ & $208(46.95)$ & $413(48.42)$ & $X 2=0.67, p=0.41$ \\
\hline \multicolumn{5}{|l|}{$\begin{array}{l}\text { Health status }{ }^{\wedge}: \mathrm{n} \\
(\%)\end{array}$} \\
\hline Excellent & $5(1.22)$ & $103(23.25)$ & $108(12.66)$ & \\
\hline Very good & $53(12.93)$ & $209(47.18)$ & $262(30.72)$ & \\
\hline Good & $116(28.29)$ & $112(25.28)$ & $228(26.73)$ & $X 2=366.63, p<0.001$ \\
\hline Fair & $168(40.98)$ & $17(3.84)$ & 185 (21.69) & \\
\hline Poor & $68(16.59)$ & $2(0.45)$ & $70(8.21)$ & \\
\hline \multicolumn{5}{|l|}{$\begin{array}{l}\text { SEIFA deciles }{ }^{+}: \mathrm{n} \\
(\%)\end{array}$} \\
\hline Low $(1-4)$ & $144(35.12)$ & $134(30.25)$ & $278(32.71)$ & \\
\hline Medium (5-7) & $110(26.83)$ & $124(27.99)$ & $234(27.43)$ & $X 2=2.50, p=0.29$ \\
\hline High (8-10) & $154(37.56)$ & $184(41.53)$ & $338(39.62)$ & \\
\hline \multicolumn{5}{|c|}{ *Wilcoxon rank-sum test with continuity correction; $\mathrm{X}^{2}$ is a Chi-squared test } \\
\hline \multicolumn{5}{|c|}{ ^Self-reported health status } \\
\hline
\end{tabular}

Table 5 presents the ranking of quality of life preferences by the percentage of points allocated to each quality of life dimension. If a dimension was ranked 1 st it received 12 points, 2nd 11 points, and so on until the 12th ranked dimension received 1 point. The order of preference rankings between the two groups differed, which suggests that the presence of a disability affects what factors are important to someone's quality of life. For the 'with disability' group the most important quality of life dimension was Control (10.91\%), whereas Contro/ was ranked 4th (9.74\%) for the 'without disability' group. In terms of ranked position based on proportion of total points allocated, the biggest differences between the groups were for the quality of life dimensions Vision (6 ranking places) and Physical mobility (4 ranking places). In both instances, the 'with disability' group valued these quality of life dimensions less than the 'without disability' group. There was agreement in the ranked order for Pain and Sleep.

Sample variance of the proportion of points allocated to each quality of life dimension was larger in the 'with disability' group $\left(S^{2}=3.74\right)$, than the 'without disability' group $\left(S^{2}=2.91\right)$. A larger sample variance indicated that there was more agreement in the rank order of quality of life dimensions within the 'with disability', group as specific dimensions consistently received more (or less) points. The consistency of how the points were allocated, resulted in a larger sample variance in the 'with disability' group. 
Table 5

Quality of life dimensions ranked by proportion (\%) of available points allocated

\begin{tabular}{|c|c|c|}
\hline Rank & With disability $(n=410)(\%)$ & Without disability $(n=443)(\%)$ \\
\hline 1 & Control (10.91) & Independence (11.19) \\
\hline 2 & Independence (10.67) & Physical mobility (10.59) \\
\hline 3 & Self-care (9.83) & Mental well-being (10.11) \\
\hline 4 & Mental well-being (9.65) & Control (9.74) \\
\hline 5 & Safety (9.51) & Vision (8.78) \\
\hline 6 & Physical mobility (8.58) & Self-care (8.03) \\
\hline 7 & Pain (8.21) & Pain (7.38) \\
\hline 8 & Social relationships (7.63) & Safety (7.4) \\
\hline 9 & Dignity (7.60) & Social relationships (7.14) \\
\hline 10 & Sleep (7.13) & Sleep (6.82) \\
\hline 11 & Vision (5.69) & Hearing (6.61) \\
\hline 12 & Hearing (4.58) & Dignity (6.21) \\
\hline
\end{tabular}

Figure 2 provides a visual representation of the differences in the proportion of points allocated to each quality of life dimension between the groups. The comparison of the proportion of points allocated indicates the relative weight assigned to each quality of life dimension and provides insight into the magnitude of differences between the two groups. The dimension Vision had the largest ranking difference between groups (ranked more highly by the 'without disability' group), and also returned the greatest difference in preference weighting (3.09\% points). The second largest percentage point difference was for the dimension Safety. Those from the 'with disability' group allocated 2.11 more percentage points to this dimension than those 'without disability'; clearly demonstrating that safety is of more importance to the quality of life of someone with a disability compared to someone without a disability. The only other dimensions where there was a $\geq 2 \%$ point difference in point allocation were in Hearing and Physical mobility. For both dimensions, the 'without disability' group identified these dimensions as more important to their quality of life than the 'with disability' group. Despite only a one rank position difference between groups for Hearing (11th vs 12th ), there was a 2.03 percentage point difference in the proportion of points allocated. For the 'with disability' group, there was a consensus that Hearing is not of high importance to their quality of life, whereas for those without a disability, although ranked lowly, there was less agreement within the group as to its importance to their quality of life. The value of Fig. 2 is that it makes it clear that there is a difference in how people with and without a disability preference different quality of life dimensions. People with a disability more highly value broader dimensions of quality of life than health status dimensions.

Table 6 presents the frequency of respondents who ranked each of the 12 quality of life dimensions 1 st ; 1 st or 2 nd ; 1 st, 2 nd or 3rd ; and 1st, 2nd, 3rd or 4th. Across both 'with disability' and 'without disability', the number one ranked quality of life dimension did not change position across the ranking groups (e.g. Rank 1; Rank 1 or 2; Rank 1, 2 or 3; Rank 1, 2, 3 or 4). For 'with disability', Control occupied the first ranked position across all groups, whereas for 'without disability' Independence remained the most popular dimension across all ranking groups.

How both groups ranked the 'Broader quality of life dimensions' and 'Health status dimensions' was different between the 'with disability' and 'without disability' groups. Across all four ranking columns, greater than 60 per cent of respondents in the 'with disability' group included a 'Broader quality of health dimension' as either their 1st, 2nd, 3rd or 4th preference. The 'Rank 1 ' column showed the biggest split between 'Broader quality of life dimensions' (70.49\%) and 'Health status dimensions' (29.51\%), and this difference continued largely into the final ranking group (64.27\% vs 35.73\%). A persistent preference for one type of quality of life dimension was less apparent across the ranking columns for 'without disability'. Rank 1 column showed a clear preference for 'Broader quality of life dimensions' (57.34\% vs $42.66 \%$ ), but this all but disappeared by the last ranking group (50.06\% vs $49.94 \%$ ). The absence of an obvious difference between broader and health status quality of life dimensions in the 'without disability' group suggests that those without a disability do not have a clear preference for a type of quality of life dimension. In contrast, the 'with disability' group demonstrated a clear preference for broader quality of life dimensions. 
Table 6

Count frequency: quality of life dimension rankings summary (up to first four)

\begin{tabular}{|c|c|c|c|c|c|c|c|c|c|c|c|c|c|c|c|c|}
\hline \multirow[t]{3}{*}{ Dimension } & \multicolumn{4}{|c|}{ Rank 1} & \multicolumn{4}{|c|}{ Rank 1 or 2} & \multicolumn{4}{|c|}{ Rank 1,2 or 3} & \multicolumn{4}{|c|}{ Rank $1,2,3$ or 4} \\
\hline & \multicolumn{2}{|c|}{$\begin{array}{l}\text { With } \\
\text { disability }\end{array}$} & \multicolumn{2}{|c|}{$\begin{array}{l}\text { Without } \\
\text { disability }\end{array}$} & \multicolumn{2}{|c|}{$\begin{array}{l}\text { With } \\
\text { disability }\end{array}$} & \multicolumn{2}{|c|}{$\begin{array}{l}\text { Without } \\
\text { disability }\end{array}$} & \multicolumn{2}{|c|}{$\begin{array}{l}\text { With } \\
\text { disability }\end{array}$} & \multicolumn{2}{|c|}{$\begin{array}{l}\text { Without } \\
\text { disability }\end{array}$} & \multicolumn{2}{|c|}{ With disability } & \multicolumn{2}{|c|}{$\begin{array}{l}\text { Without } \\
\text { disability }\end{array}$} \\
\hline & $\mathrm{n}$ & $\%$ & $\mathrm{n}$ & $\%$ & $\mathrm{n}$ & $\%$ & $\mathrm{n}$ & $\%$ & $\mathrm{n}$ & $\%$ & $\mathrm{n}$ & $\%$ & $\mathrm{n}$ & $\%$ & $\mathrm{n}$ & $\%$ \\
\hline \multicolumn{17}{|c|}{$\begin{array}{l}\text { Broader quality of life } \\
\text { dimensions }\end{array}$} \\
\hline Control & 100 & 24.39 & 53 & 11.96 & 155 & 18.90 & 103 & 11.63 & 204 & 16.59 & 154 & 11.59 & 239 & 14.57 & 198 & 11.17 \\
\hline Independence & 68 & 16.59 & 132 & 29.80 & 138 & 16.83 & 197 & 22.23 & 185 & 15.04 & 235 & 17.68 & 236 & 14.39 & 273 & 15.41 \\
\hline Self-care & 49 & 11.95 & 20 & 4.51 & 104 & 12.68 & 38 & 4.29 & 160 & 13.01 & 78 & 5.87 & 187 & 11.40 & 122 & 6.88 \\
\hline Safety & 43 & 10.49 & 23 & 5.19 & 90 & 10.98 & 47 & 5.30 & 145 & 11.79 & 75 & 5.64 & 184 & 11.22 & 104 & 5.87 \\
\hline $\begin{array}{l}\text { Social } \\
\text { relationships }\end{array}$ & 15 & 3.66 & 15 & 3.39 & 42 & 5.12 & 48 & 5.42 & 67 & 5.45 & 78 & 5.87 & 110 & 6.71 & 109 & 6.15 \\
\hline Dignity & 14 & 3.41 & 11 & 2.48 & 35 & 4.27 & 26 & 2.93 & 63 & 5.12 & 47 & 3.54 & 98 & 5.98 & 81 & 4.57 \\
\hline Total & 289 & 70.49 & 254 & 57.34 & 564 & 68.78 & 459 & 51.81 & 824 & 66.99 & 667 & 50.19 & 1054 & 64.27 & 887 & 50.06 \\
\hline \multicolumn{17}{|l|}{$\begin{array}{l}\text { Health status } \\
\text { dimensions }\end{array}$} \\
\hline Pain & 43 & 10.49 & 28 & 6.32 & 69 & 8.41 & 60 & 6.77 & 89 & 7.24 & 90 & 6.77 & 119 & 7.26 & 121 & 6.83 \\
\hline $\begin{array}{l}\text { Mental well- } \\
\text { being }\end{array}$ & 40 & 9.76 & 53 & 11.96 & 83 & 10.12 & 105 & 11.85 & 141 & 11.46 & 158 & 11.89 & 192 & 11.71 & 211 & 11.91 \\
\hline $\begin{array}{l}\text { Physical } \\
\text { mobility }\end{array}$ & 17 & 4.15 & 52 & 11.74 & 45 & 5.49 & 123 & 13.88 & 75 & 6.10 & 189 & 14.22 & 126 & 7.68 & 243 & 13.71 \\
\hline Sleep & 8 & 1.95 & 15 & 3.39 & 27 & 3.29 & 31 & 3.50 & 53 & 4.31 & 54 & 4.06 & 79 & 4.82 & 73 & 4.12 \\
\hline Vision & 8 & 1.95 & 31 & 7.00 & 19 & 2.32 & 76 & 8.58 & 29 & 2.36 & 114 & 8.58 & 43 & 2.62 & 159 & 8.97 \\
\hline Hearing & 5 & 1.22 & 10 & 2.26 & 13 & 1.59 & 32 & 3.61 & 19 & 1.54 & 57 & 4.29 & 27 & 1.65 & 78 & 4.40 \\
\hline Total & 121 & 29.51 & 189 & 42.66 & 256 & 31.22 & 427 & 48.19 & 406 & 33.01 & 662 & 49.81 & 586 & 35.73 & 885 & 49.94 \\
\hline $\begin{array}{l}\text { Test of } \\
\text { difference } \\
\text { (With vs } \\
\text { Without } \\
\text { disability) }\end{array}$ & \multicolumn{4}{|c|}{$Z^{b}=-4.842, p=0.000$} & \multicolumn{4}{|c|}{$Z^{b}=-7.351, p=0.000$} & \multicolumn{4}{|c|}{$Z^{b}=-8.512, p=0.000$} & \multicolumn{4}{|c|}{$Z^{b}=-8.171, p=0.000$} \\
\hline \multicolumn{17}{|c|}{ a Two-sample Wilcoxon rank-sum (Mann-Whitney) test } \\
\hline${ }^{b} Z=Z$ statistic & & & & & & & & & & & & & & & & \\
\hline
\end{tabular}

\section{Discussion}

The main findings from this study indicate that people with disability' place relatively high importance on quality of life dimensions which can be categorised as broader quality of life dimensions relative to health status focused dimensions. Although the 'without disability' group ranked Independence and Control as their 1st and 2nd most important quality of life dimensions (same as the 'with disability' group), when the ranking order of all 12 dimensions was compared between groups, it was clear that the 'with disability' group placed more importance overall on broader dimensions of quality of life. Inspecting the ranking points system which captured quality of life preferences (Fig. 2), it is evident that people with a disability place relatively more importance on quality of life dimensions Safety, Self-care and Dignity, in comparison with people without a disability. Several previous studies have identified potential differences in the conceptualisation of quality of life for people with a disability relative to people without a disability (24-27). The novel contribution of this study is the application of an empirical ranking technique to quantify the relative importance of salient quality of life dimensions (represented in commonly applied generic preference-based measures of quality of life for people) in these two populations.

Identifying what aspects of quality of life are most important to people with a disability is an important first step in the development of tools which are sensitive to their preferences. Townsend-White, Pham and Vassos (2011) conducted a systematic review of 24 quality of life measures designed to measure changes in the quality of life of people with intellectual disabilities. Six quality of life measures were identified as being psychometrically 
sound. However, the authors concluded that there is not a universally accepted 'gold-standard' for measuring the quality of life of adults with an intellectual disability (27). A recent systematic review by Bray, Spencer and Edwards (2020) explored which instruments are commonly used to assess the quality of life of individuals with congenital mobility disabilities. The authors also concluded that current quality of life instruments are insufficient to capture those quality of life domains of most importance to people with a disability (28). Both systematic reviews reviewed nonpreference-based quality of life measures that are not amenable to economic evaluation. In this study we mapped quality of life dimensions from three commonly applied generic preference-based measures and investigated their relative importance to people with and without disability. The addition of the ranking exercise draws out differences in quality of life preferences between those with and without disability. Further research should be directed at investigating the preferences of people with a disability across a larger set of quality of life dimensions.

King et al. (2012) conducted semi-structured interviews with 62 elderly adults (mean age of 78) with late-life disability and revealed four domains which were important to their quality of life: physical, psychological, spiritual or religious and social (29). Where King et al. (2012) followed an iterative bottom-up process, Yeung and Breheny (2021) attempted to build a model to identify which, of 13 different factors, most affect the quality of life of a person with a disability. A total of 4028 community-dwelling New Zealanders were included in their study, of which 452 (11\%) self-reported having a disability. Respondents first rated their quality of life against a five-point response scale. Via regression analysis, a model was developed which explained $56 \%$ of the variance in self-reported quality of life across the 'with disability' and 'without disability' groups (30). The model identified that self-reported physical health, mental health, purpose in life and independence had statistically significant effects on explaining the variance in respondents' self-reported quality of life. Although different quality of life dimensions were explored in our study, the results of the study by Yeung and Breheny (2021) concur with our study's finding that Mental well-being and physical heath characteristics (e.g. Vision, Hearing and Physical mobility) were of less importance to a person's quality of life, relative to the preferences of a sample of people without a disability. However, the methods applied in each study were quite different, which limits the ability to directly compare the results.

Within Australia, the NDIS is expected to support over half a million people with a disability by the end of 2022-23 (31). To improve the ongoing evaluation of the NDIS (and other international disability insurance programs) it will be important to improve the tools used to measure the effectiveness of interventions in policy and practice for people with a disability. Quality of life is a key outcome indicator for the NDIS, for people with a disability and their families, and for providers of disability care services in Australia and internationally. It is therefore highly important that any new preference-based measure of quality of life for people with disability is designed from its inception to fully incorporate the views and preferences of people with a disability.

As with any study of this nature, there were several limitations which are important to highlight. The quality of life dimensions which featured in this study were based on the content of three existing generic preference-based measures of quality of life. Given that people with a disability were not interviewed to ascertain what dimensions may be important to them, the 12 dimensions used in this study may not reflect all of the key quality of life dimensions important to people with a disability. Across both population groups, people from a higher socio-economic status were slightly more represented than those from lower socio-economic statuses. According to the 2016 Australian census, most Australians were classified as enjoying a medium level of advantage according to the SEIFA's Index of Relative Socio-economic Advantage and Disadvantage score (32). A final limitation is that respondents were recruited via an online panel, survey company (PureProfile). Whilst PureProfile's panel membership base is large and diverse, individuals registered to PureProfile are not entirely representative of and are likely more computer literate overall than the general Australian population.

\section{Conclusions}

In conclusion, this empirical study indicates that the quality of life preferences for people with a disability differ to those without a disability. In general, people with a disability place more importance on broader quality of life dimensions including Safety, Self-care, Controland Independence, than physical health attributes including Vision, Hearing and Physical mobility. As quality of life is a key outcome for economic evaluation and for assessing the impact of disability care policy and practice in Australia and internationally, it is important that new preference-based quality of life measures are developed which are sufficiently sensitive to, and incorporate the quality of life preferences of people with a disability.

\section{Abbreviations}

AQoL-4D: Australian Quality of life 4 Dimension; ASCOT: Adult Social Care Outcomes Toolkit; ICC: Intraclass Correlation Coefficient; MAUls: Multiattribute utility instruments; NDIS: National Disability Insurance Scheme; QALYs: Quality adjusted life years; SEIFA: Socio-Economic Indexes for Areas; YLD: Years living with a disability

\section{Declarations}

\section{Ethics approval and consent to participate}

Ethics approval for this study was provided by the Human Research Ethics Committee at Flinders University (Project Number: 8631).

\section{Consent for publication}


Not applicable.

\section{Availability of data and materials}

The datasets generated and analysed during this study are not publicly available due to Flinders University ethics requirements, but are available from the corresponding author on reasonable request.

\section{Competing interests}

The authors declare that they have no competing interests.

\section{Funding}

All funding sources for this study were provided by the College of Nursing and Health Sciences, Flinders University.

\section{Author's contributions}

$\mathrm{JR}, \mathrm{CH}, \mathrm{RW}$ and GC conceptualised the study and developed the survey. MC and CMK conducted the analysis with JR, $\mathrm{CH}, \mathrm{RW}$ and GC providing oversight and guidance. MC produced the tables and figures and wrote the first draft of the manuscript. All authors provided critical review and approved the final manuscript.

\section{Acknowledgements}

Not applicable.

\section{References}

1. Mavromaras K, Moskos M, Mahuteau S, Isherwood L, Goode A, Walton H, et al. Evaluation of the NDIS. 2018. https://apo.org.au/sites/default/files/resource-files/2018/04/apo-nid143516-1215586.pdf. Accessed 21 May 2021.

2. Dickinson H, Glasby J. The personalisation agenda: Implications for the third sector, Third Sector Research Centre. Working paper 30.2010. http://epapers.bham.ac.uk/795/. Accessed 21 May 2021.

3. Brazier J, Ratcliffe J, Saloman J, Tsuchiya A. Measuring and Valuing Health Benefits for Economic Evaluation. $2^{\text {nd }}$ ed. New York: Oxford University Press; 2017.

4. Grewal I, Lewis J, Flynn T, Brown J, Bond J, Coast J. Developing attributes for a generic quality of life measure for older people: Preferences or capabilities? Soc Sci Med. 2006;1;62(8):1891-901.

5. Milte R, Ratcliffe J, Chen G, Lancsar E, Miller M, Crotty M. Cognitive overload? An exploration of the potential impact of cognitive functioning in discrete choice experiments with older people in health care. Value Heal. 2014;17(5):655-9.

6. Ratcliffe J, Lancsar E, Flint T, Kaambwa B, Walker R, Lewin G, et al. Does one size fit all? Assessing the preferences of older and younger people for attributes of quality of life. Qual Life Res. 2017;26(2):299-309.

7. Whitehurst DG, Suryaprakash N, Engel L, Mittmann N, Noonan VK, Dvorak MFS, et al. Perceptions of individuals living with spinal cord injury toward preference-based quality of life instruments: A qualitative exploration. Health Qual Life Outcomes. 2014;12(1).

8. Preede L, Saebu M, Perrin PB, Nyquist A, Dalen H, Bautz-Holter E, et al. One-year trajectories of mental and physical functioning during and after rehabilitation among individuals with disabilities. Health Qual Life Outcomes. 2015;13(1).

9. Mehdipour A, O'Hoski S, Beauchamp MK, Wald J, Kuspinar A. Content validity of preference-based measures for economic evaluation in chronic obstructive pulmonary disease. Health Qual Life Outcomes. 2021;19(1).

10. Torrance GW. Measurement of health state utilities for economic appraisal. A review. J Health Econ. 1986;5(1):1-30.

11. Pequeno NPF, Pequeno NPF, Cabral NL de A, Marchioni DM, Lima SCVC, Lyra C de O. Quality of life assessment instruments for adults: a systematic review of population-based studies. Health Qual Life Outcomes. 2020;18(1).

12. McCaffrey N, Kaambwa B, Currow DC, Ratcliffe J. Health-related quality of life measured using the EQ-5D-5L: South Australian population norms. Health Qual Life Outcomes. 2016;14(1).

13. Herdman M, Gudex C, Lloyd A, Janssen M, Kind P, Parkin D, et al. Development and preliminary testing of the new five-level version of EQ-5D (EQ5D-5L). Qual Life Res. 2011;20(10):1727-36.

14. Netten A, Burge P, Malley J, Potoglou D, Towers AM, Brazier J, et al. Outcomes of social care for adults: Developing a preference-weighted measure. Health Technol Assess (Rockv). 2012;16(16):1-165.

15. World Health Organization. World Health Statistics 2021: monitoring health for the SDGs. https://reliefweb.int/sites/reliefweb.int/files/resources/whs-2021_20may.pdf. Accessed 26 May 2021.

16. Australian Institute of Health and Welfare. People with disability in Australia, Income support. 2020. https://www.aihw.gov.au/reports/disability/people-with-disability-in-australia/contents/income-and-finance/income-support. Accessed 9 Jun 
2021.

17. Pink B. An introduction to Socio-Economic Indexes for Areas (SEIFA), 2006. 2008. http://www.abs.gov.au/ausstats/abs@.nsf/cat/2039.0. Accessed 22 May 2021.

18. Pink B. Socio-Economic Indexes for Areas (SEIFA) - Technical Paper 2006. 2008. https://www.ausstats.abs.gov.au/ausstats/subscriber.nsf/0/72283F45CB86E5FECA2574170011B271/\$File/2039055001_socioeconomic\%20indexes\%20for\%20areas\%20(seifa)\%20-\%20technical\%20paper_2006.pdf. Accessed 22 May 2021.

19. Pateman K, Huang J, Ford PJ, Mutch A, Freeman CR, Taing MW. Consumer perspectives on pharmacy staff roles in providing oral health services in Australia. Heal Soc Care Community. 2020 Mar 1;28(2):524-32.

20. Armiento R, Hoq M, Kua E, Crawford N, Perrett KP, Elia S, et al. Impact of Australian mandatory 'No Jab, No Pay' and 'No Jab, No Play' immunisation policies on immunisation services, parental attitudes to vaccination and vaccine uptake, in a tertiary paediatric hospital, the Royal Children's Hospital, Melbourne. Vaccine. 2020;38(33):5231-40.

21. Field, Andy; Miles, Jeremy; Field Z. Discovering Statistics Using R. London: Sage Publications Ltd; 2013.

22. Bulmer M. Principles of Statistics. 2nd ed. London: Oliver \& Boyd; 1967.

23. Koo TK, Li MY. A Guideline of Selecting and Reporting Intraclass Correlation Coefficients for Reliability Research. J Chiropr Med. 2016;15(2):15563.

24. Hensel E, Rose J, Stenfert Kroese B, Banks-Smith J. Subjective judgements of quality of life: A comparison study between people with intellectual disability and those without disability. J Intellect Disabil Res. 2002;46(2):95-107.

25. Schalock RL, Brown I, Brown R, Cummins RA, Felce D, Matikka L, et al. Erratum: Conceptualization, Measurement, and Application of Quality of Life for Persons With Intellectual Disabilities: Report of an International Panel of Experts (Mental Retardation 40:6 (470)). Ment Retard. 2003;41(1):66.

26. Neumayer R, Bleasdale M. Personal lifestyle preferences of people with an intellectual disability. J Intellect Dev Disabil. 1996;21(2):91-114.

27. Townsend-White C, Pham ANT, Vassos M V. Review: A systematic review of quality of life measures for people with intellectual disabilities and challenging behaviours. J Intellect Disabil Res. 2012;56(3):270-84.

28. Bray N, Spencer LH, Edwards RT. Preference-based measures of health-related quality of life in congenital mobility impairment: A systematic review of validity and responsiveness. Health Econ Rev. 2020;10(1):1-38.

29. King J, Yourman L, Ahalt C, Eng C, Knight SJ, Pérez-Stable EJ, et al. Quality of life in late-life disability: “I Don’t Feel Bitter because I Am in a Wheelchair." J Am Geriatr Soc. 2012;60(3):569-76.

30. Yeung P, Breheny M. Quality of life among older people with a disability: the role of purpose in life and capabilities. Disabil Rehabil. 2021;43(2):181-91.

31. World Health Organization; World Bank. World report on disability 2011. Vol. 105. 2012.

32. Australian Bureau of Statistics. Technical Paper Socio-Economic Indexes for Areas (SEIFA) 2016. Technical Paper. 2018. http://www.ausstats.abs.gov.au/ausstats/subscriber.nsf/0/22CEDA8038AF7A0DCA257B3B00116E34/\$File/2033.0.55.001 seifa 2011 technical paper.pdf. Accessed 30 June 2021.

\section{Table}

Table 1 is not available with this version.

\section{Figures}




\begin{tabular}{|c|}
\hline $\begin{array}{l}\text { SLEEP } \\
\text { Being able to sleep without difficulty most of the time }\end{array}$ \\
\hline $\begin{array}{l}\text { INDEPENDENCE } \\
\text { Being able to spend your time as you want, doing things you value and } \mathrm{e}\end{array}$ \\
\hline $\begin{array}{c}\text { PHYSICAL MOBILITY } \\
\text { Being able to get around your home and community by yourself without any }\end{array}$ \\
\hline $\begin{array}{l}\text { MENTAL WELL-BEING } \\
\text { Not feeling anxious, worried or depressed } \\
\end{array}$ \\
\hline $\begin{array}{l}\text { CONTROL } \\
\text { Having as much control over your daily life as you would want }\end{array}$ \\
\hline $\begin{array}{c}\text { SELF-CARE } \\
\text { Feeling clean and being able to present yourself in the way you like }\end{array}$ \\
\hline $\begin{array}{c}\text { PAIN } \\
\text { Having no pain or discomfort } \\
\end{array}$ \\
\hline $\begin{array}{c}\text { VISION } \\
\text { Being able to see normally }\end{array}$ \\
\hline $\begin{array}{c}\text { HEARING } \\
\text { Being able to hear normally }\end{array}$ \\
\hline $\begin{array}{c}\text { SAFETY } \\
\text { Feeling as safe as you want }\end{array}$ \\
\hline $\begin{array}{l}\text { SOCIAL-RELATIONSHIPS } \\
\text { Having as much social contact as you want with people you like }\end{array}$ \\
\hline $\begin{array}{c}\text { DIGNITY } \\
\text { Having help which makes you think and feel better about yourself }\end{array}$ \\
\hline
\end{tabular}

\section{Figure 1}

Quality of life dimensions ranking task In thinking about your quality of life and your overall well-being a number of factors may be important to you. Below are a number of items described on a series of cards which may contribute to improving the quality of life of older people (e.g. health, social relationships, independence, personal control etc.). Please read each card carefully and then rank each card in order of its importance to your quality of life and overall well-being by clicking on the card and dragging it into place according to its level of importance. Please place the most important item at the top of the list and the least important item at the bottom of the list. Please note that there are no wrong or right answers - we are simply interested in your views

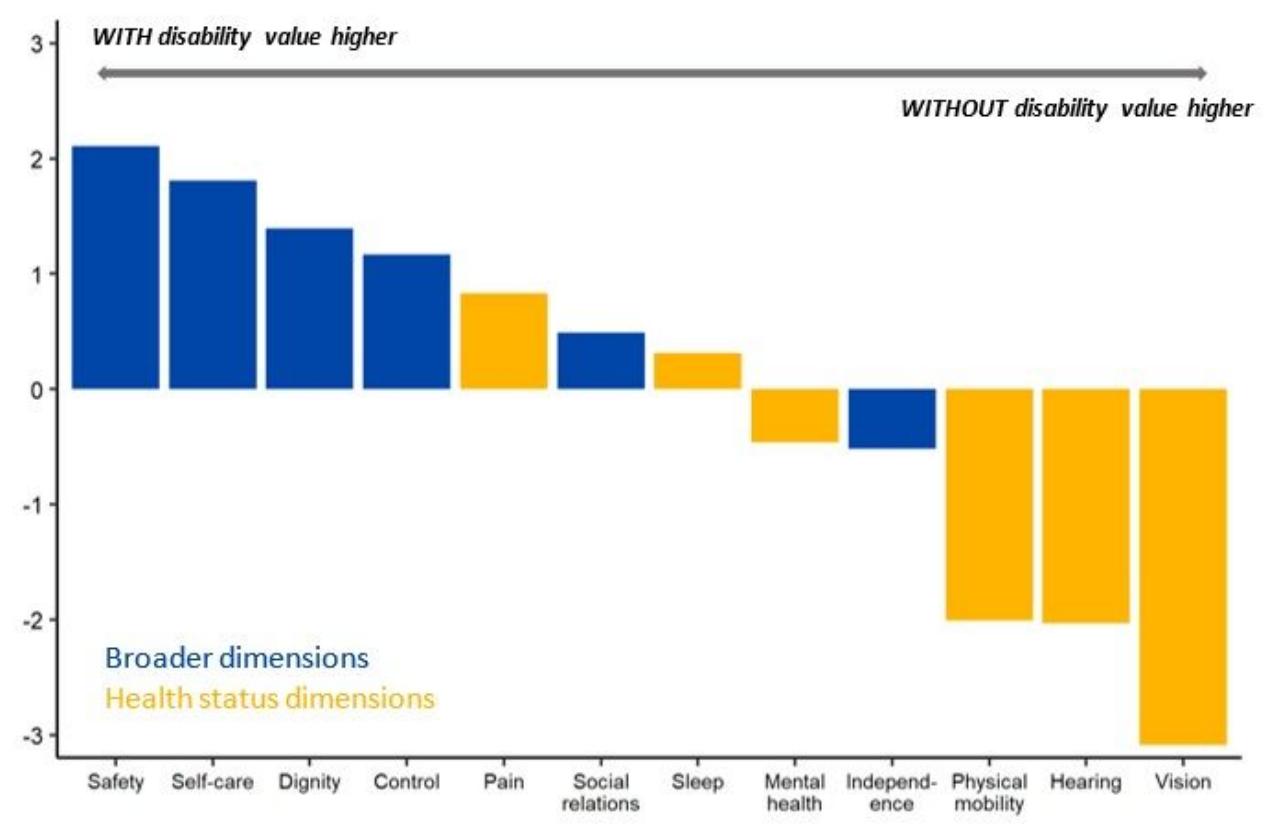

Figure 2

Percentage point difference in the relative importance of quality of life dimensions by disability status. Note: Percentage point difference shown ('with disability' - 'without disability') 


\section{Supplementary Files}

This is a list of supplementary files associated with this preprint. Click to download.

- Appendix.docx 